Rechtsmedizin 2021 · 31:217-225

https://doi.org/10.1007/s00194-021-00491-8

Angenommen: 30. März 2021

Online publiziert: 10. Mai 2021

(c) Der/die Autor(en) 2021

\author{
Manuel Pfeifer ${ }^{1,2}$ - Angelique Greb ${ }^{1}$ Thomas Bajanowski' $\cdot$ Micaela Poetsch $^{1}$ \\ ${ }^{\prime}$ Institut für Rechtsmedizin, Universitätsklinikum Essen, Essen, Deutschland \\ ${ }^{2}$ Institut für Rechtsmedizin, Medizinische Fakultät Dresden, TU Dresden, Dresden, Deutschland
}

\title{
Performance des PyroMark Q48 FX Age Assay auf zwei unterschiedlichen Pyrosequenzierplattformen
}

\section{Einleitung}

Die Möglichkeit der Altersschätzung anhand einer DNA-Methylierungsanalyse erlangte in den letzten Jahren eine immer größere Bedeutung für die forensische Genetik, in Deutschland insbesondere durch die Erweiterung der Strafprozessordnung Ende 2019. Zahlreiche Studien veröffentlichten Altersschätzungsmodelle mit unterschiedlichen Altersmarkern und Markerkombinationen mit Schätzgenauigkeiten („Mean-absolutedeviation" [MAD]-Wert) unter 5 Jahren $[1,2,5,7-11,17]$. Dabei muss jedoch berücksichtigt werden, dass die jeweiligen Modelle aufgrund der Variabilität der DNA-Methylierung meist nur für einen bestimmten Zell- bzw. Gewebetyp etabliert wurden [4]. Ein weiterer kritischer Punkt bei der DNA-Methylierungsanalyse ist der erforderliche Einsatz einer hohen DNA-Menge, da insbesondere während der Bisulfitkonvertierung ein Anteil der eingesetzten genomischen DNA durch Aufreinigungs- und Degradationsprozesse verloren geht [16]. Somit basieren viele dieser Studien auf der Untersuchung von Blutproben, da hier große DNA-Mengen gewonnen werden können. In der forensischen Analyse von Tatortspuren allerdings steht auch in Proben, die einer einzigen Person zugeordnet werden können, meist nur deutlich weniger DNA zur Verfügung, als für die Bisulfitkonvertierung empfohlen wird [4]. Neben der Sensitivität muss auch die Reproduzierbarkeit solch einer Methode in anderen Laboren ge- geben sein. Hier zeigten Vergleiche, dass es teilweise $\mathrm{zu}$ deutlichen Unterschieden bei Verwendung des gleichen Modells in verschiedenen Laboren kommen kann [2]. Zur Standardisierung der Altersschätzung über die DNA-Methylierungsanalyse wurde durch die Fa. Qiagen (Hilden, Deutschland) der PyroMark Q48 FX Age Assay, bestehend aus 5 Altersmarkern der Gene ELOVL2, KLF14, TRIM59, FHL2 und C1orf132 entwickelt. Im Rahmen der Validierung dieses Altersschätzungsassays sollte ein Feldtest in verschiedenen Laboren durchgeführt werden, um die Performance zwischen den einzelnen Laboren zu untersuchen. Der Assay wurde speziell für die Anwendung auf dem Pyrosequenziergerät PyroMark Q48 Autoprep entwickelt. In vielen forensischen Laboren ist dieses jedoch nicht verfügbar bzw. sind ältere Pyrosequenziergeräte vorhanden, sodass in dieser Studie zusätzlich ein Vergleich mit einem anderen Pyrosequenziergerät, dem PyroMark Q96 MD, durchgeführt wurde.

\section{Material und Methoden}

\section{Proben}

Im Rahmen von Abstammungsuntersuchungen wurden 28 Mundschleimhautabriebe (MSA) von Personen in 5 Altersklassen ( 0 bis 5, 20 bis 25, 35 bis 40, 65 bis 70 und 85 bis 90 Jahre) entnommen, die $\mathrm{zu}$ Forschungszwecken freigegeben wurden (Ethikvotum: 16-7113-BO).
Darüber hinaus wurden 15 Blutproben von Verstorbenen aus 5 verschiedenen Altersgruppen 0 bis 5, 20 bis 25, 35 bis 40,65 bis 70 und 90 bis 95 Jahre asserviert, die während Sektionen im Institut für Rechtsmedizin Essen entnommen wurden (Ethikvotum: 15-6345-BO).

\section{Extraktion, Quantifizierung und Bisulfitkonvertierung der DNA}

Die genomische DNA der MSA wurde mithilfe der SwabSolution (Fa. Promega, Mannheim, Deutschland) laut Herstellerangaben extrahiert.

Für die Blutproben wurde das DNA IQ Casework Pro Kit and Casework Extraction Kit (Fa. Promega) in Verbindung mit dem Maxwell-16 ${ }^{\circledR}$-Gerät eingesetzt, um die genomische DNA zu isolieren.

Die Quantifizierung der genomischen DNA erfolgte mithilfe des PowerQuant ${ }^{\mathrm{TM}}$ System (Fa. Promega) im Applied Biosystems ${ }^{\circledR} 7500$ Real-Time PCR System (Fa. Applied Biosystems, Darmstadt, Deutschland) gemäß den Herstellerangaben. Jeweils $2 \mu \mathrm{l}$ der isolierten DNA wurde in Duplikaten für die Real-Time PCR eingesetzt.

Zur Bestimmung des DNA-Methylierungsgrades wurden $200 \mathrm{ng}$ (Blutproben) bzw. $100 \mathrm{ng}$ (MSA) genomische DNA mithilfe von Bisulfit unter Verwendung des EpiTect Fast DNA Bisulfite Kit (Fa. Qiagen) entsprechend den Herstellerangaben behandelt und in $40 \mu \mathrm{l}$ eluiert. 
Tab. 1 Gen-Loci und Primer-Konzentration der 5 Altersmarker

\begin{tabular}{|c|c|c|c|}
\hline Gen-Locus & Referenz & Zu analysierende Sequenz (vor Bisulfitbehandlung) & Primer-Konz. \\
\hline C1orf132 & [18] & CGCCGCCTGCGCAGACCCAAATCTTGGTCC & $0,8 \mu \mathrm{M}$ \\
\hline KLF14 & [18] & $\begin{array}{l}\text { CGCGTTCTTTCTTCTGCCGGCGAGCCAGGTAATGGT } \\
\text { AACAGAG }\end{array}$ & $0,2 \mu \mathrm{M}$ \\
\hline TRIM59 & [18] & CGTCGGCCACCGGCGC & $0,3 \mu \mathrm{M}$ \\
\hline ELOVL2 & [18] & AGCCGGCGCCGGTTTCGCGCGGCGGCTCAA & $0,6 \mu \mathrm{M}$ \\
\hline FHL2 & [18] & $\begin{array}{l}\text { TCGGGAGCGTCGCCTCCGGCGTGGGCTCTCGGGCGCG } \\
\text { AGTTTCGGACGAGGCCTGGG }\end{array}$ & $0,2 \mu \mathrm{M}$ \\
\hline
\end{tabular}

\section{Analyse der DNA-Methylierung} mithilfe der Pyrosequenzierung

Die DNA-Methylierungsanalyse wurde mithilfe der Pyrosequenzer PyroMark Q48 Autoprep und PyroMark Q96 MD (beide Fa. Qiagen) durchgeführt. Zuvor wurden die zu untersuchenden Zielregionen mithilfe des PyroMark PCR Kit (Fa. Qiagen) laut Herstellerangaben unter Einsatz von $10 \mathrm{ng}$ bisulfitkonvertierter DNA amplifiziert. Die einzelnen Zielregionen sowie deren Primer-Konzentrationen sind in • Tab. 1 aufgelistet. Die PCR umfasste folgende Einzelschritte: Enzymaktivierung bei $95^{\circ} \mathrm{C}$ für $15 \mathrm{~min}, 50$ Zyklen, bestehend aus einem Denaturierungsschritt bei $95^{\circ} \mathrm{C}$ für $30 \mathrm{~s}$, ,annealing “ bei $48^{\circ} \mathrm{C}$ bis $52,5^{\circ} \mathrm{C}$ $\left(+0,5^{\circ} \mathrm{C} /\right.$ Zyklus $)$ für $30 \mathrm{~s}$ und „elongation" bei $72^{\circ} \mathrm{C}$ für $30 \mathrm{~s}$ und einem abschließenden Verlängerungsschritt bei $72^{\circ} \mathrm{C}$ für $10 \mathrm{~min}$.

Die Aufreinigung und Immobilisierung der PCR-Produkte erfolgten automatisiert im PyroMark Q48 Autoprep. Hingegen wurde für die Immobilisierung und Präparation der PCR-Produkte für den PyroMark Q96 MD die PyroMark ${ }^{\circledR}$ Q96 Vacuum Workstation laut Herstellerangaben genutzt (Fa. Qiagen). Für die Pyrosequenzierung wurden für beide Geräte $10 \mu \mathrm{l}$ PCR-Produkt und $0,4 \mu \mathrm{M}$ (PyroMark Q48 Autoprep) bzw. 0,3 $\mu \mathrm{M}$ (PyroMark Q96 MD) Sequenzier-Primer eingesetzt.

Die relative Menge an methylierter DNA wurde über das Verhältnis der Peak-Höhen durch die jeweilige PyroMark Software (Fa. Qiagen) bestimmt. Es wurden nur Daten verwendet, die eine vollständige Bisulfitkonvertierung innerhalb des Pyrogramms zeigten.

\section{Test auf Richtigkeit und Messpräzision}

Der Test auf Richtigkeit und Messpräzision wurde mithilfe des PyroMark Q48 Autoprep durchgeführt. Zur Einschätzung der Präzision der DNA-Methylierungswerte wurden zunächst 2 KontrollDNA $\quad\left(\right.$ EpiTect $^{\circledR}$ Control DNA methyliert und EpiTect $^{\circledR}$ Control DNA unmethyliert [Qiagen, Hilden, Deutschland]) in unterschiedlichen Verhältnisanteilen $(0 \%$, $50 \%, 100 \%$ methyliert) in Bezug auf alle 5 Cytosin-Phosphat-Guanin(CpG)Stellen analysiert. Pro Mix und CpGStelle wurde die PCR in Triplikaten durchgeführt, um die Messgenauigkeit zu beurteilen. Die Mittelwerte und die Standardabweichung der Triplikate wurden berechnet und die quantifizierte DNA-Methylierung mit den bekannten DNA-Methylierungsanteilen gemäß den Herstellerangaben für die Kontroll-DNA verglichen.

\section{Statistische Analyse}

Die angegebenen DNA-Methylierungswerte entsprechen den Mittelwerten aus einer Dreifachbestimmung der PCR. Die Fehlerwerte sind als Standardabweichung berechnet. Als Software wurde Microsoft Excel 2010 angewendet. Für die Bestimmung der Signifikanzen zwischen den DNA-Methylierungswerten des PyroMark Q48 Autoprep und des PyroMark Q96 MD wurde ein gepaarter T-Test mithilfe der Software SPSS (Version 27) angewendet.

\section{Ergebnisse}

\section{Test auf Richtigkeit und Messpräzision}

Die Bestimmung der DNA-Methylierungsanteile der einzelnen Verdünnungen der Kontroll-DNA zeigte eine sehr starke lineare Korrelation $(r>0,96)$ zwischen der gemessenen und der theoretischen DNA-Methylierung für alle $5 \mathrm{CpG}$ Stellen. Jedoch unterschieden sich die quantifizierten DNA-Methylierungswerte von den theoretisch eingestellten Werten der Kontroll-DNA (• Abb. 1). Für die vollständig bzw. die teilweise methylierte und die komplett unmethylierte Kontroll-DNA wurde eine DNAMethylierung von 70 bis $85 \%$, von 30 bis $43 \%$ und $<10 \%$ gemessen (- Abb. 1). Die berechneten Standardabweichungen der Triplikate lagen unter 5\% mit Ausnahme für die theoretische zu $100 \%$ methylierte Kontroll-DNA in der CpG-Stelle von FHL2 (• Abb. 1). Hier schwankten die gemessenen DNA-Methylierungswerte zwischen 59 und $80 \%$.

\section{DNA-Methylierungsanalyse mithilfe von PyroMark Q48 Autoprep und PyroMark Q96 MD}

Zum Vergleich der beiden Pyrosequenziergeräte wurden pro Gerät aus einem Bisulfitkonvertierungsansatz 3 PCR für jede CpG-Stelle durchgeführt und die DNA-Methylierungswerte der MSAund Blutproben einander gegenübergestellt.

\section{Mundschleimhautabriebe}

Die Methylierungsanalysen ergaben für 4 CpG-Stellen (ELOVL2, KLF14, FHL2 und TRIM59) eine positive bzw. für die CpG-Stelle des Gens C1orf132 eine negative Korrelation zum chronologischen Alter (• Abb. 2). Die Gegenüberstellung der DNA-Methylierungswerte beider Geräte zeigt teilweise starke Unterschiede (• Abb. 2). So war der DNAMethylierungsgrad aller CpG-Stellen für den PyroMark Q48 Autoprep geringer als für den PyroMark Q96 MD (- Abb. 2). Es ließen sich signifikante Unterschiede $(p<0,05)$ der DNA-Methylierung zwischen beiden Geräten in 
Rechtsmedizin $2021 \cdot 31: 217-225$ https://doi.org/10.1007/s00194-021-00491-8

(c) Der/die Autor(en) 2021

\section{Pfeifer · A. Greb · T. Bajanowski · M. Poetsch}

\section{Performance des PyroMark Q48 FX Age Assay auf zwei unterschiedlichen Pyrosequenzierplattformen}

\section{Zusammenfassung}

Hintergrund. Der PyroMark Q48 FX Age Assay (Qiagen, Hilden, Deutschland) wurde von der Fa. Qiagen $\mathrm{GmbH}$ als kommerziell erhältliches Kit für die molekulare Altersschätzung auf der Grundlage von DNA-Methylierungsanalysen mithilfe eines PyroMark Q48 Autoprep (Qiagen, Hilden, Deutschland) vorgestellt. Fragestellung. Vergleichbarkeit und Anwendbarkeit des PyroMark Q48 FX Age Assay auf den 2 unterschiedlichen Pyrosequenzierplattformen PyroMark Q48 Autoprep und PyroMark Q96 MD.

Material und Methoden. Es wurden 28 Mundschleimhautabriebe (MSA) und 15 Blutproben mithilfe des PyroMark Q48 FX Age Assay auf 2 Pyrosequenzierplattformen analysiert und jeweils eine Altersschätzung über das Schätzmodell von Zbiec-Piekarska et al. (2015) durchgeführt.

Ergebnisse. Die DNA-Methylierungswerte in den 5 Cytosin-Phosphat-Guanin(CpG)Stellen wiesen beim Vergleich beider Geräte signifikante Unterschiede auf, wobei die DNA-Methylierungslevel des PyroMark Q96 MD sowohl in MSA als auch in den Blutproben höher waren als für den PyroMark Q48 Autoprep. So zeigte sich bei den MSA eine mittlere Abweichung der DNAMethylierungswerte der beiden Geräte von $10,6 \%$, wohingegen diese bei den Blutproben $7,4 \%$ betrug. Bei der Altersschätzung der Blutproben konnten jedoch keine deutlichen Unterschiede zwischen den Pyrosequenzern im Hinblick auf die Schätzgenauigkeit identifiziert werden. Hier beträgt die mittlere absolute Abweichung 7,9 (PyroMark Q48 Autoprep) bzw. 8,1 Jahre (PyroMark Q96 MD). Schlussfolgerung. Die aufgetretenen Unterschiede in den DNA-Methylierungswerten sowohl bei den Blutproben als auch den MSA verdeutlichen die Schwierigkeit der Vergleichbarkeit von DNA-Methylierungswerten aus unterschiedlichen Geräten. Für die Verwendung dieses Assays mit anderen Pyrosequenziergeräten müssten weitere Proben analysiert werden, um mögliche signifikante Unterschiede detektieren zu können.

\section{Schlüsselwörter}

DNA-Methylierung · Altersschätzung .

Mundschleimhaut $\cdot$ Blut $\cdot$ CpG-Stellen

\section{Performance of the PyroMark Q48 FX age assay on two different pyrosequencing platforms}

\section{Abstract}

Background. The PyroMark Q48 FX age assay (Qiagen $\mathrm{GmbH}$ ) was introduced as a commercially available kit for molecular age estimation by analyzing DNA methylation with the PyroMark Q48 Autoprep device. Objective. Performance and comparability of the PyroMark Q48 FX age assay using the two different pyrosequencing platforms PyroMark Q48 Autoprep and PyroMark Q96 MD were investigated.

Material and methods. In this study 28 buccal swabs and 15 blood samples were analyzed with the PyroMark Q48 FX age assay on the two pyrosequencing platforms and age was estimated using the estimation model created by Zbiec-Piekarska et al. (2015).
Results. The comparison of the DNA methylation values between both pyrosequencing devices showed significant differences in all $5^{\prime}$-cytosine-phosphate-guanine-3' (CpG) sites $(n=5)$, whereby the DNA methylation values for the PyroMark Q96MD were higher than those for the PyroMark Q48 Autoprep for both buccal swabs and blood samples. A mean difference of the DNA methylation values was $10.6 \%$ for buccal swab samples and $7.4 \%$ for blood samples when comparing the 2 pyrosequencing devices. Regarding the age estimation of blood samples, no significant differences between the two pyrosequencing platforms could be identified with a mean absolute deviation of 7.9 years and 8.1 years for the PyroMark Q48 Autoprep and PyroMark Q96 MD, respectively.

Conclusion. The differences in DNA methylation values for both blood samples and buccal swabs presented here emphasize the difficulties regarding the comparison of DNA methylation results provided by different devices. For an application of the PyroMark Q48 FX age assay using pyrosequencing platforms other than PyroMark Q48 Autoprep, additional samples have to be analyzed to be able to detect possible significant differences between the devices.

\section{Keywords}

DNA methylation - Age estimation - Buccal mucosa $\cdot$ Blood $\cdot$ CpG sites den Altersgruppen 0 bis 5, 20 bis 25, 35 bis 40,65 bis 70 und 85 bis 90 Jahre für die CpG-Stellen in ELOVL2, FHL2 und C1orf132 erkennen. Ebenso bestanden diese Differenzen in den Altersgruppen 20 bis 25,65 bis 70 und 85 bis 90 Jahre für TRIM59 bzw. 20 bis 25 und 35 bis 40 Jahre für KLF14.

Für die Beurteilung der Güte des $\mathrm{Zu}$ sammenhangs zwischen der DNA-Methylierung und dem chronologischen Alter kann das Bestimmtheitsmaß herangezogen werden. Auch hierbei ergaben sich teilweise deutliche Unterschiede zwischen beiden Geräten. Die Ausnahme bildete die CpG-Stelle des Gens ELOVL2 mit 0,88 (PyroMark Q48 Autoprep) bzw. 0,84 (PyroMark Q96 MD), sodass 88 bzw. $84 \%$ der Variation der DNA-Methylierung durch die Änderung des chronologischen Alters erklärt werden konnten [3]. Für die CpG-Stellen von KLF14 und C1orf132 ließen sich nur leicht höhere Bestimmtheitsmaße für den PyroMark Q48 Autoprep mit 0,74 (KLF14) bzw. 0,50 (C1orf132) im Vergleich zum Py-
roMark Q96 MD mit 0,62 (KLF14) bzw. 0,41 (C1orf132) berechnen. Größere Differenzen zeigten die Bestimmtheitsmaße der CpG-Stellen von FHL2 und TRIM59. Mit 0,19 (FHL2) und 0,69 (TRIM59) lagen diese bei dem PyroMark Q48 Autoprep deutlich unterhalb derer des PyroMark Q96 MD mit 0,46 (FHL2) bzw. 0,90 (TRIM59).

\section{Blutasservate}

Die Änderung der DNA-Methylierung in Abhängigkeit vom chronologischen 


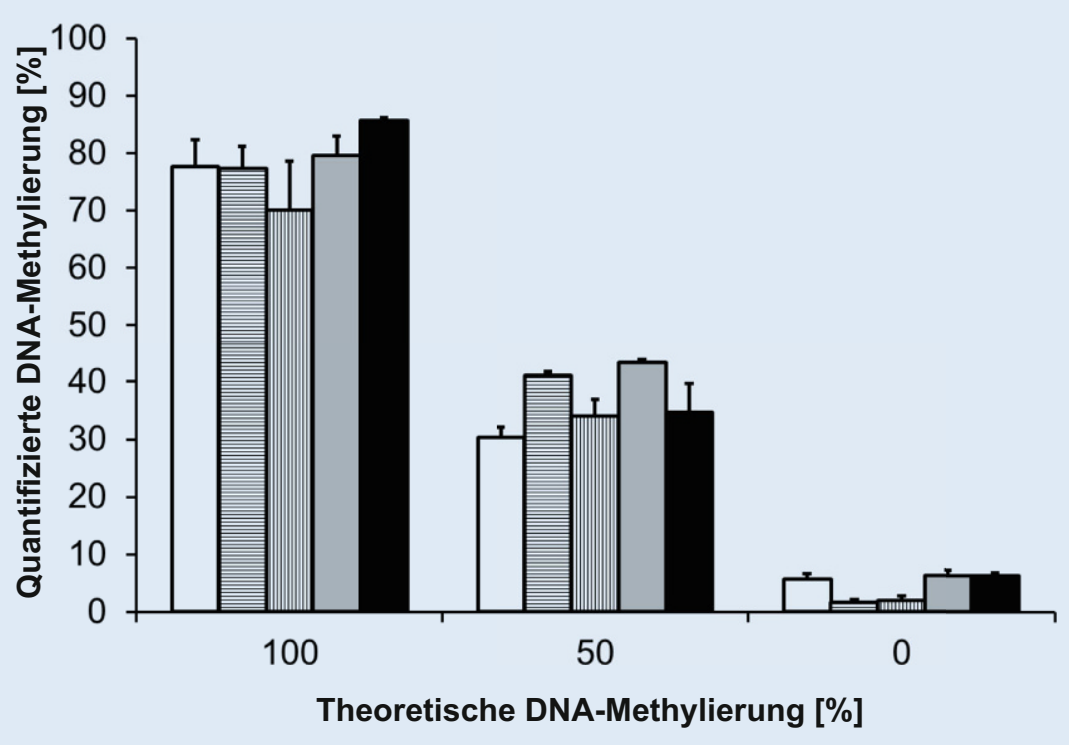

Abb. 1 ॥ DNA-Methylierungsanalyse der Kontroll-DNA für die einzelnen Cytosin-Phosphat-Guanin(CpG)-Stellen mithilfe des PyroMark Q48 Autoprep. ELOVL2 (farblos), KLF14 (waagerechte Streifen), FHL2 (senkrechte Streifen), C1orf132 (grau), TRIM59 (schwarz)

Alter wies in allen $5 \mathrm{CpG}$-Stellen für die Blutasservate denselben Trend wie in den MSA auf. Die Unterschiede der DNA-Methylierung zwischen beiden Geräte waren nicht so deutlich wie bei den MSA (• Abb. 3). Für FHL2 konnten keine und lediglich in den Altersgruppen 35 bis 40 (ELOVL2), 20 bis 25 (KLF14) und 65 bis 70 Jahre (TRIM59) signifikanten Unterschiede $(p<0,05)$ zwischen der DNA-Methylierung beider Geräte gefunden werden. Für die CpG-Stelle im Gen C1orf132 zeigten die Altersklassen 20 bis 25,35 bis 40 und 65 bis 70 Jahre signifikante Unterschiede.

Die Bestimmtheitsmaße der CpGStellen für die Blutasservate waren deutlich höher als für die MSA. Mit 0,93 bzw. 0,92 (PyroMark Q48 Autoprep) und 0,94 bzw. 0,92 (PyroMark Q96 MD) zeigten ELOVL2 bzw. C1orf132 die besten Werte. Die restlichen Bestimmtheitsmaße betrugen 0,83 (PyroMark Q48 Autoprep) und 0,80 (PyroMark Q96 MD), 0,78 (PyroMark Q48 Autoprep) und 0,88 (PyroMark Q96 MD) und 0,73 (PyroMark Q48 Autoprep) und 0,85 (PyroMark Q96 MD) für die CpGStellen von KLF14, FHL2 bzw. TRIM59.

\section{Altersschätzungen}

Blutasservate Für die Altersschätzung der 5 CpG-Stellen wurde das Schätzmodell von Zbiec-Piekarska et al. angewendet [18]. Mithilfe dieses Modells wurde das Schätzalter von den Individuen berechnet, von denen Blutproben vorlagen. Dabei fanden sich teilweise hohe Differenzen zwischen dem geschätzten und dem chronologischen Alter (- Tab. 2). Auffallend ist, dass für die Altersklassen 20 bis 25 und 35 bis 40 Jahre das Schätzalter in allen Proben und für beide Methoden höher ist als das chronologische Alter. Hingegen ist in der Altersgruppe 90 bis 95 Jahre das Schätzalter niedriger; hier traten auch die höchsten Differenzen auf. Obwohl die DNA-Methylierungswerte zwischen den beiden Geräten unterschiedlich waren, weisen die berechneten Schätzgenauigkeiten kaum Unterschiede auf. Durch die Bildung des Mittelwerts der Differenzen konnte die MAD mit Werten von 7,9 (PyroMark Q48 Autoprep) bzw. 8,1 Jahren (PyroMark Q96 MD) bestimmt werden.

Mundschleimhautabriebe Obwohl das Schätzmodell von Zbiec-Piekarska et al. für Blutproben etabliert wurde, wurden die DNA-Methylierungswerte der MSA ebenfalls verwendet, um das jeweilige
Schätzalter der Probanden zu bestimmen (๑ Tab. 3). Es ergaben sich teilweise deutliche Unterschiede zu den chronologischen Altersangaben der Probanden. So wurde eine MAD von 12,7 bzw. 10,5 Jahren für den PyroMark Q48 Autoprep bzw. den PyroMark Q96 MD berechnet. Obwohl die MAD-Werte zwischen den beiden Pyrosequenzern ähnlich waren, zeigten sich in den einzelnen Altersgruppen deutliche Differenzen zwischen dem chronologischen und geschätzten Alter. So wies die jüngste Altersklasse (0 bis 5 Jahre) im Mittel eine Unterschätzung des biologischen Alters für den PyroMark Q48 Autoprep bzw. eine Überschätzung für den PyroMark Q96 MD auf. Für die Altersklassen 20 bis 25 bzw. 35 bis 40 Jahren war das geschätzte Alter für beide Pyrosequenziergeräte höher als das biologische Alter. Hierbei waren die Differenzen für den PyroMark Q96 MD höher als für den PyroMark Q48 Autoprep. Im Gegensatz dazu wurde das biologische Alter in den Altersklassen 65 bis 70 und 85 bis 90 Jahre mithilfe beider Geräte niedriger geschätzt, mit höheren Unterschieden für den PyroMark Q48 Autoprep.

\section{Diskussion}

\section{Test auf Richtigkeit und Messpräzision}

Voraussetzung für eine erfolgreiche Quantifizierung der DNA-Methylierung ist eine präzise Bestimmung des Anteils an methylierter DNA an einer CpGStelle. Hier zeigen die Ergebnisse dieser Studie, dass eine Differenzierung unterschiedlicher DNA-Methylierungsgrade innerhalb der CpG-Motive möglich ist, jedoch die Messgenauigkeiten insbesondere bei sehr hohen und niedrigen DNAMethylierungsleveln schwanken. Die in dieser Studie untersuchten CpG-Stellen wurden ebenso durch Daunay et al. unter Verwendung der gleichen kommerziell erhältlichen Kontroll-DNA analysiert [2]. Hier waren die gemessenen DNAMethylierungswerte der $100 \%$ theoretisch methylierten Kontroll-DNA bei allen 5 CpG-Stellen leicht höher [2]. Für die restlichen 2 Methylierungslevel (50\% und $0 \%$ ) fanden sich hingegen ähnliche Werte [2]. Daunay et al. interpretierten, 

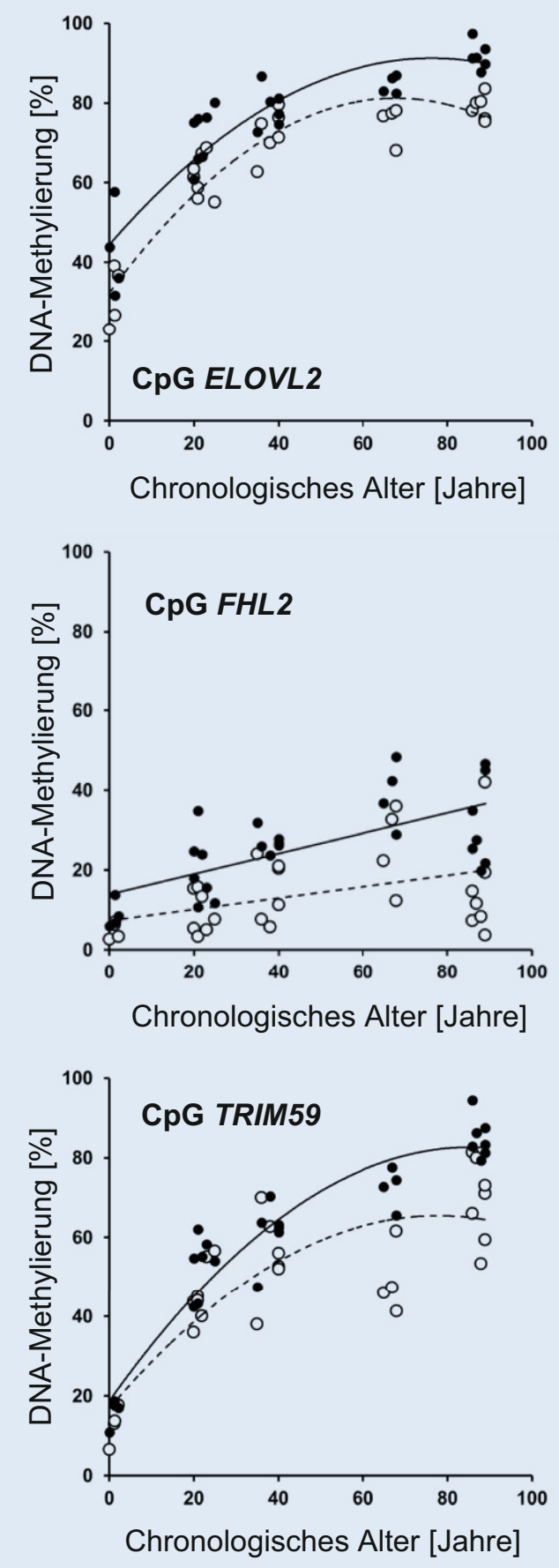
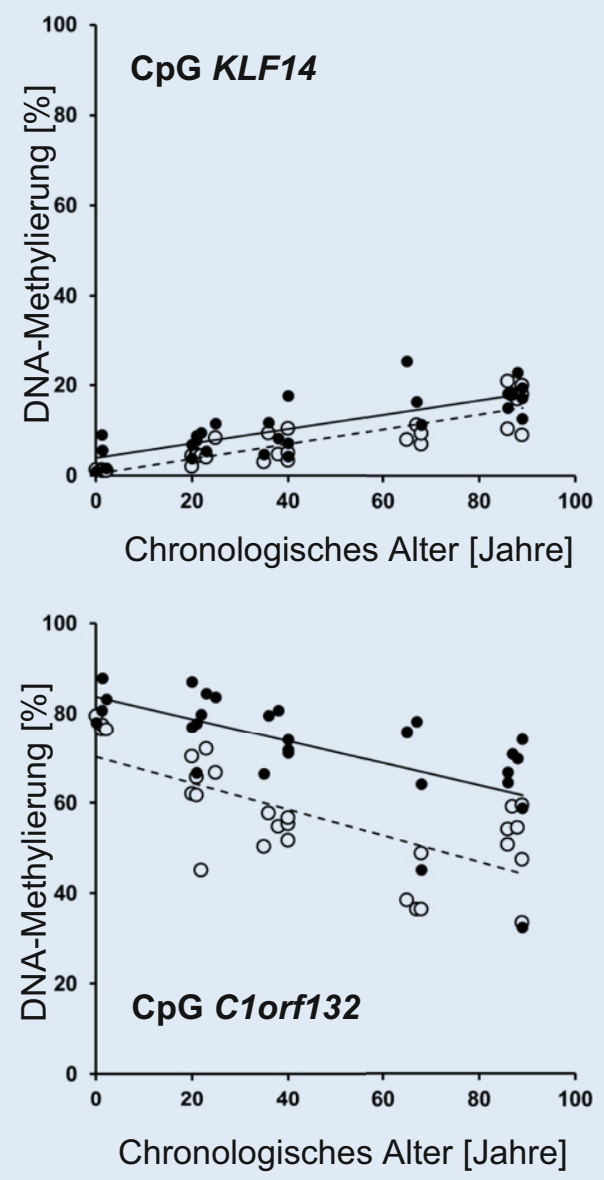

Abb. $2<$ DNA-Methylierungsanalyse der Mundschleimhautabriebe aller 5 Altersklassen mithilfe des PyroMark Q48. Autoprep (farblos) und des PyroMark Q96 MD (schwarz). CpG Cytosin-Phosphat-Guanin dass insbesondere für DNA-Standards von $25 \%$ iger, $50 \%$ iger und $75 \%$ iger DNA-Methylierung ein schwacher PCRBias vorliegt, sodass das unmethylierte Allel bevorzugt amplifiziert wird [2, 4].

Die berechneten Standardabweichungen liegen mit einer Ausnahme unterhalb des Grenzwerts von $5 \%$ für technische Replikate zwischen separaten PCR-Am- plifikationen und zeigen somit eine gute Messpräzision [15].

\section{DNA-Methylierungsanalyse mithilfe PyroMark Q48 Autoprep und PyroMark Q96 MD}

Signifikante Unterschiede der DNA-Methylierungswerte für alle 5 untersuchten CpG Stellen, wie sie in dieser Stu- die aufgetreten sind, wurden in der Literatur bereits mehrfach in Form von Differenzen zwischen einzelnen Laboren beschrieben [2, 13]. Hingegen konnten in dieser Studie Variationen zwischen 2 verschiedenen Pyrosequenziergeräten aus ein und demselben Labor gezeigt werden. Obwohl pro Gerät 2 getrennte Bisulfitkonvertierungsansätze von einer Probe verwendet wurden, waren die Che- 

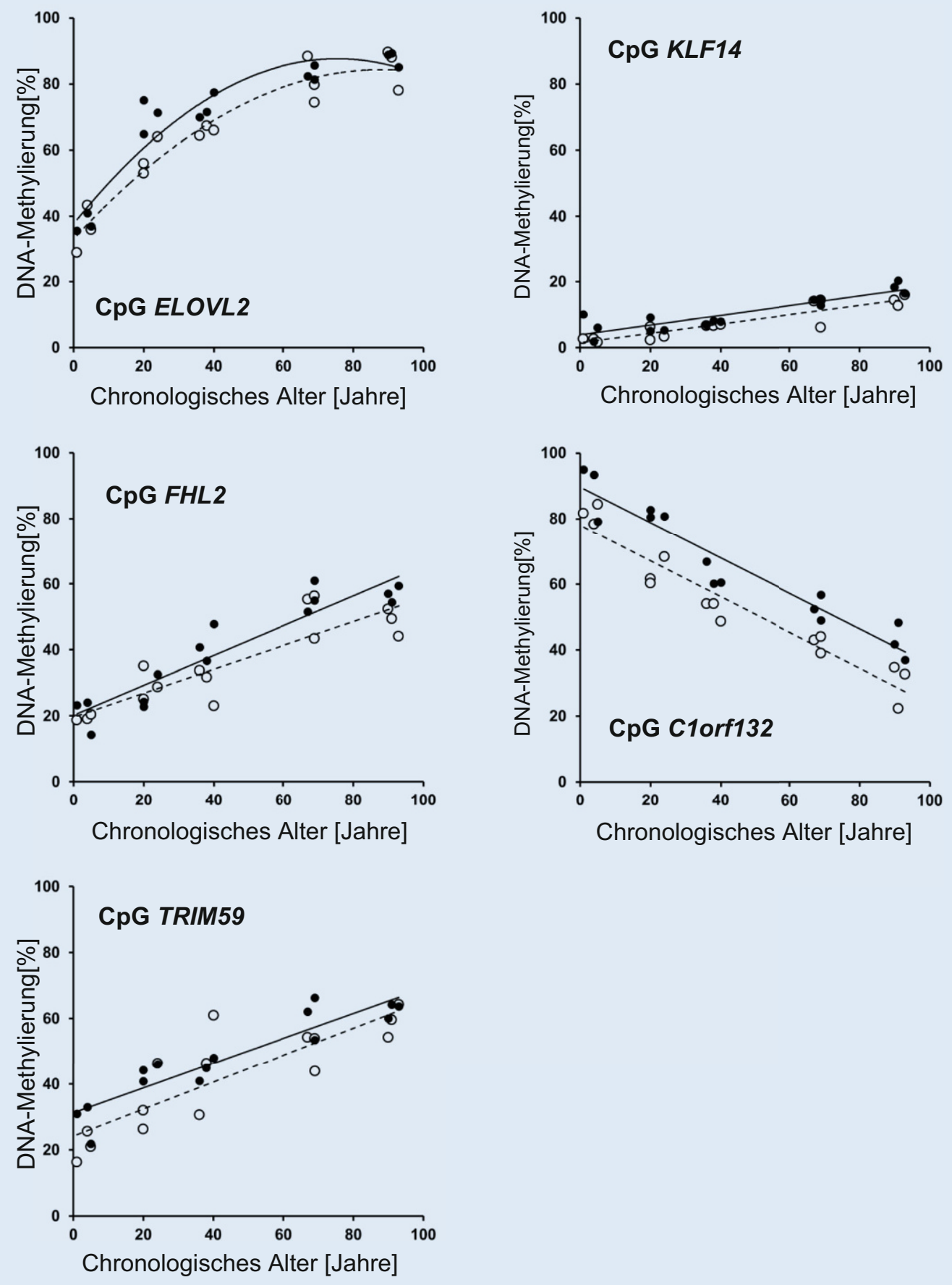

mikalien sowie die Konvertierungs- und PCR-Bedingungen identisch. Lediglich die Aufbereitung der PCR-Produkte für die anschließende Sequenzierung war an das jeweilige Gerät angepasst. Diese Ergebnisse belegen die Schwierigkeiten in der Vergleichbarkeit von DNA-Methylierungsergebnissen, die mit verschiedenen Geräten erzielt wurden. Eine Möglichkeit zur Verringerung der Variabili- tät besteht in einer Normierung der Daten. Hierzu müsste eine Kontrollprobe, mit konstantem DNA-Methylierungsgehalt, für jeden Lauf und auf den verschiedenen Geräten mitgeführt werden. Ein entsprechender Normierungsfaktor kann aus den Unterschieden der Läufe bzw. der Geräte berechnet und dann für die Anpassung der DNA-Methylierungsdaten genutzt werden. Die Erstellung ei-
Abb. $3<$ DNA-Methylierungsanalyse der Blutproben aller 5 Altersklassen mithilfe des PyroMark Q48. Autoprep (farblos) und des PyroMark Q96 MD (schwarz). CpG CytosinPhosphat-Guanin 


\begin{tabular}{|c|c|c|c|c|c|}
\hline \multirow{2}{*}{$\begin{array}{l}\text { Proben } \\
\text { Nr. }\end{array}$} & \multirow{2}{*}{$\begin{array}{l}\text { Chronolo- } \\
\text { gisches Alter } \\
\text { (Jahre) }\end{array}$} & \multicolumn{2}{|c|}{ PyroMark Q48 Autoprep } & \multicolumn{2}{|c|}{ PyroMark Q96 MD } \\
\hline & & $\begin{array}{l}\text { Schätzalter } \\
\text { (Jahre) }\end{array}$ & $\begin{array}{l}\text { Differenz } \\
\text { (Chronologisches Alter-Schätzalter) }\end{array}$ & $\begin{array}{l}\text { Schätzalter } \\
\text { (Jahre) }\end{array}$ & $\begin{array}{l}\text { Differenz } \\
\text { (Chronologisches Alter-Schätzalter) }\end{array}$ \\
\hline 1 & 1 & $-0,6$ & $-1,6$ & 9,5 & $-8,5$ \\
\hline 2 & 4 & 10,2 & $+6,2$ & 6,5 & $-2,5$ \\
\hline 3 & 5 & 2,7 & $-2,3$ & 7,5 & $-2,5$ \\
\hline 4 & 20 & 26,7 & $+6,7$ & 29,5 & $-9,5$ \\
\hline 5 & 20 & 26,5 & $+6,5$ & 33,2 & $-13,1$ \\
\hline 6 & 24 & 32,5 & $+8,5$ & 33,9 & $-9,9$ \\
\hline 7 & 36 & 36,9 & $+0,9$ & 40,0 & $-4,0$ \\
\hline 8 & 38 & 42,7 & $+4,7$ & 44,4 & $-6,3$ \\
\hline 9 & 40 & 46,7 & $+6,7$ & 50,4 & $-10,4$ \\
\hline 10 & 67 & 70,5 & $+3,5$ & 66,3 & $+0,7$ \\
\hline 11 & 69 & 55,2 & $-13,8$ & 63,7 & $+5,3$ \\
\hline 12 & 69 & 64,1 & $-4,9$ & 69,9 & $-0,9$ \\
\hline 13 & 90 & 73,7 & $-16,3$ & 83,3 & $+7,7$ \\
\hline 14 & 91 & 76,8 & $-14,2$ & 64,2 & $+28,8$ \\
\hline 15 & 93 & 71,4 & $-21,6$ & 78,2 & $+14,8$ \\
\hline$M A D$ & & 7,9 & & 8,1 & \\
\hline \multicolumn{6}{|c|}{$M A D_{\text {"mean absolute deviation" }}$} \\
\hline
\end{tabular}

\section{Blutasservate und Mundschleim- hautabriebe}

Die für diesen Assay verwendeten CpGStellen wurden der Publikation von Zbiec-Piekarska et al. übernommen [18]. Hier wurde die DNA-Methylierung ebenfalls in Blutproben untersucht, mit dem Ergebnis, dass ähnliche Bestimmtheitsmaße für ELOVL2, C1orf132 und TRIM59 von $0,83,0,79$ und 0,74 berechnet werden konnten [18]. Daunay et al. verwendeten in ihrer Studie ebenfalls dieselben Altersmarker, jedoch waren die Bestimmtheitsmaße deutlich niedriger als die Werte der vorliegenden und der Studie von Zbiec-Piekarska et al. [2]. Auch hier zeigte die CpG-Stelle des Gens ELOVL2 das höchste Bestimmtheitsmaß mit 0,630, für C1orf132 jedoch wurde nur ein Wert von 0,45 berechnet [18]. Daunay et al. verwendeten für ihre Analysen den PyroMark Q96 MD, wohingegen Zbiec-Piekarska et al. das PyroMark-Q24 Gerät nutzten [2, 18]. Daunay et al. beschrieben, dass die DNA-Methylierungswerte, insbesondere der CpGStellen von ELOVL2 und C1orf132, ein höheres Level im Vergleich zu den Studien von Zbiec-Piekarska et al. aufwiesen, sodass sich dadurch die Unterschiede in den Bestimmtheitsmaßen erklären lassen würden [2]. Auch die Unterschiede der Bestimmtheitsmaße in der Analyse der Mundschleimhautabriebe lassen sich v.a. auf die höheren Standardabweichungen der DNA-Methylierung bei dem PyroMark Q48 Autoprep zwischen den Asservaten innerhalb der Altersgruppen 35 bis 40,65 bis 70 und 85 bis 90 Jahre zurückführen.

\section{Altersschätzungen}

Blutasservate Die Schätzung des biologischen Alters erfolgte anhand des Modells von Zbiec-Piekarska et al. [18]. Die Zunahme der Differenzen zwischen Schätzalter und chronologischem Alter aufgrund des „epigenetic drift“ wurde bereits durch verschiedene Studien belegt $[6,12,14]$. Eine Vergleichbarkeit der geschätzten Alter mit Ergebnissen aus anderen Studien verläuft über die Bildung der MAD. Hier sind die Werte dieser Studie gut vergleichbar mit den von Daunay et al. publizierten Ergebnissen mit 7,2 Jahren, jedoch deutlich höher als die von Zbiec-Piekarska et al. berichteten Werte mit 3,1 Jahren [2, 18]. Diese Ergebnisse belegen die enormen Schwierigkeiten bei der Adaptation von publizierten Methoden in anderen Laboren, die bereits in einer früheren Studie für einen anderen Assay gezeigt werden konnten [13].
Mundschleimhautabriebe Die höheren MAD-Werte und auch die einzelnen Differenzen verdeutlichen die Ungenauigkeit des Schätzungsmodells, wenn es auf Mundschleimhautzellen als Ausgangsmaterial angewandt wird. Darüber hinaus spiegelt sich hier auch die Zunahme der Differenzen zwischen chronologischem und geschätztem Alter wider, die durch andere Arbeitsgruppen ebenfalls beobachtet worden ist, und v. a. durch die Zunahme von verschiedenen äußeren und inneren Faktoren auf den Organismus zu erklären ist [12, 14]. Zur Minimierung dieses Problems müssten weitaus mehr Proben analysiert werden, um dann mit diesen zusätzlichen Daten das Schätzungsmodell anzupassen.

\section{Schlussfolgerung}

Das verwendete Q48 FX Age Assay ist v. a. für die Analyse von Spurenmaterial designt worden, um weitere Ermittlungshinweise auf unbekannte Personen zu erlangen. Die untersuchte Probenmenge ist zu klein, um definitive Aussagen über die Anwendung dieses Assays treffen zu können, wenn die Ergebnisse auch zeigen, dass Schwierigkeiten bei dem Einsatz dieses Assays auf anderen Geräten bzw. für andere Zelltypen zu erwarten 
Tab. 3 Schätzung des biologischen Alters mithilfe des Schätzmodells von Zbiec-Piekarska et al. [18] für die Probanden, von denen Mundschleimhautabriebe vorlagen

\begin{tabular}{|c|c|c|c|c|c|}
\hline Proben & & PyroMark Q & toprep & PyroMark Q & \\
\hline & $\begin{array}{l}\text { gisches Alter } \\
\text { (Jahre) }\end{array}$ & $\begin{array}{l}\text { Schätzalter } \\
\text { (Jahre) }\end{array}$ & $\begin{array}{l}\text { Differenz } \\
\text { (Chronologisches Alter-Schätzalter) }\end{array}$ & $\begin{array}{l}\text { Schätzalter } \\
\text { (Jahre) }\end{array}$ & $\begin{array}{l}\text { Differenz } \\
\text { (Chronologisches Alter-Schätzalter) }\end{array}$ \\
\hline 1 & 0,05 & $-10,5$ & $+10,5$ & 1,5 & $-1,5$ \\
\hline 2 & 1,25 & 0,9 & $+0,4$ & 16,3 & $-15,1$ \\
\hline 3 & 1,41 & $-5,1$ & $+6,5$ & 0,0 & $+1,4$ \\
\hline 4 & 2,25 & 0,2 & $+2,0$ & $-1,0$ & $+3,2$ \\
\hline 5 & 20 & 20,8 & $-0,8$ & 27,6 & $-7,6$ \\
\hline 6 & 20 & 31,3 & $-11,3$ & 32,6 & $-12,6$ \\
\hline 7 & 21 & 28,8 & $-7,8$ & 49,5 & $-28,5$ \\
\hline 8 & 21 & 25,1 & $-4,1$ & 28,6 & $-7,6$ \\
\hline 9 & 22 & 37,6 & $-15,6$ & 36,2 & $-14,2$ \\
\hline 10 & 23 & 31,0 & $-8,0$ & 34,8 & $-11,8$ \\
\hline 11 & 25 & 31,2 & $-6,2$ & 39,8 & $-14,8$ \\
\hline 12 & 35 & 34,4 & $+0,6$ & 39,5 & $-4,5$ \\
\hline 13 & 36 & 48,6 & $-12,6$ & 50,8 & $-14,8$ \\
\hline 14 & 38 & 40,8 & $-2,9$ & 45,9 & $-7,9$ \\
\hline 15 & 40 & 44,6 & $-4,6$ & 46,9 & $-6,9$ \\
\hline 16 & 40 & 41,8 & $-1,8$ & 41,1 & $-1,1$ \\
\hline 17 & 40 & 48,2 & $-8,2$ & 53,7 & $-13,7$ \\
\hline 18 & 65 & 51,4 & $+13,6$ & 67,1 & $-2,1$ \\
\hline 19 & 67 & 58,0 & $+9,0$ & 63,2 & $+3,8$ \\
\hline 20 & 68 & 45,2 & $+22,8$ & 57,9 & $+10,1$ \\
\hline 21 & 68 & 55,6 & $+12,4$ & 68,6 & $-0,6$ \\
\hline 22 & 86 & 53,9 & $+32,1$ & 71,9 & $+14,1$ \\
\hline 23 & 86 & 64,5 & $+21,5$ & 72,1 & $+13,9$ \\
\hline 24 & 87 & 61,8 & $+25,2$ & 68,5 & $+18,5$ \\
\hline 25 & 88 & 53,8 & $+34,2$ & 67,4 & $+20,6$ \\
\hline 26 & 89 & 64,8 & $+24,2$ & 78,3 & $+10,7$ \\
\hline 27 & 89 & 55,5 & $+33,5$ & 65,0 & $+24,0$ \\
\hline 28 & 89 & 65,9 & $+23,1$ & 81,7 & $+7,3$ \\
\hline$M A D$ & & 12,7 & & 10,5 & \\
\hline
\end{tabular}

sind. Darüber hinaus lassen die in dieser Studie dargestellten Ergebnisse den Rückschluss zu, dass der Assay für dieses Anwendungsgebiet nutzbar ist, da eine unbekannte Person mit einer gewissen Wahrscheinlichkeit einer bestimmten Altersklasse ( 0 bis 20; 20 bis 40,40 bis 60 Jahre usw.) zugeordnet werden kann. Für die Altersklasse von 20 bis 40 Jahren, der auch ein Großteil der Tatverdächtigen zuzuordnen ist, konnte die geringste MAD von 5,6 Jahren ermittelt werden. Um eine Steigerung der Sensitivität zu erhalten, müssen Analysen weiterer Probanden in diesem Altersbereich erfolgen, mit deren Daten die Berechnungsformel anschließend angepasst wird. Des Weite- ren wäre es denkbar, altersklassenspezifische Modelle aufzustellen. So könnte eine altersklassenübergreifende Formel zunächst einen ersten Hinweis auf ein ungefähres biologisches Alter geben, das anschließend durch ein weiteres Modell (der spezifischen Altersklasse) verbessert werden könnte. Gerade in der Spurenanalyse stellen die Qualität und Quantität der aufgefundenen DNA jedoch eine große Limitierung dar, der nur durch eine Verbesserung der Bisulfitkonvertierung im Sinne eines deutlich erhöhten Anteils an verwendbarer konvertierter DNA im Verhältnis zur eingesetzten DNA oder durch die Entwicklung eines MultiplexAnsatzes entgegengewirkt werden kann.
Die Verwendung von MSA resultiert in einer deutlichen Verschlechterung der Altersschätzung, sodass die Erweiterung auf andere Gewebearten nicht empfohlen wird. Hierfür sollten eine andere Markerkombination sowie ein daraus verändertes Berechnungsmodell eingesetzt werden.

Sowohl bei den MSA als auch bei den Blutproben zeigen die Ergebnisse deutliche DNA-Methylierungsunterschiede zwischen beiden Pyrosequenziergeräten in allen Altersklassen. Dieser Effekt verdeutlicht die Schwierigkeit der Vergleichbarkeit von DNA-Methylierungswerten, die nur durch eine geeignete Normierung, durch den Einsatz von 


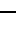

Kontrollproben mit konstantem DNAMethylierungsgehalt, realisiert werden kann. Für eine Anwendbarkeit des Q48 FX Age Assay mithilfe anderer Pyrosequenziergeräte müssten weitere Proben untersucht werden, um evtl. signifikante Abweichungen auch in den geschätzten Altern identifizieren zu können.

\section{Korrespondenzadresse}

Prof. Dr. rer. nat. Micaela Poetsch

Institut für Rechtsmedizin, Universitätsklinikum Essen

Hufelandstr. 55, 45122 Essen, Deutschland micaela.poetsch@uk-essen.de

Danksagung. Ein Dankeschön geht an die Fa. Qiagen GmbH für die Bereitstellung der Reagenzien und des PyroMark Q48 FX Age Assay, inklusive aller Primer, sowie die Beratung und Unterstützung währen des Feldtests. Außerdem bedanken wir uns bei Herrn Prof. Dr. Winfried Siffert (Institut für Pharmakogenetik, des Universitätsklinikums Essen, Deutschland) für die Bereitstellung des Pyrosequenzers und Dr. Birte Möhlendick, Iris Manthey, Stephanie Büscher und Grit Müller für deren technische Unterstützung.

Förderung. Diese Forschung erhielt keine spezifischen Zuschüsse von Fördereinrichtungen im öffentlichen, kommerziellen oder gemeinnützigen Sektor.

Funding. Open Access funding enabled and organized by Projekt DEAL.

\section{Einhaltung ethischer Richtlinien}

Interessenkonflikt. M. Pfeifer, A. Greb, T. Bajanowski und M. Poetsch geben an, dass kein Interessenkonflikt besteht.

Alle verwendeten Proben wurden nach Zustimmung der medizinischen Ethikkommission der Universität Duisburg-Essen im Einklang mit der Deklaration von Helsinki und den nationalen Richtlinien sowie für die Mundschleimhautabriebe nach Einverständniserklärung entnommen.

Open Access. Dieser Artikel wird unter der Creative Commons Namensnennung 4.0 International Lizenz veröffentlicht, welche die Nutzung, Vervielfältigung, Bearbeitung, Verbreitung und Wiedergabe in jeglichem Medium und Format erlaubt, sofern Sie den/die ursprünglichen Autor(en) und die Quelle ordnungsgemäß nennen, einen Link zur Creative Commons Lizenz beifügen und angeben, ob Änderungen vorgenommen wurden.

Die in diesem Artikel enthaltenen Bilder und sonstiges Drittmaterial unterliegen ebenfalls der genannten Creative Commons Lizenz, sofern sich aus der Abbildungslegende nichts anderes ergibt. Sofern das betreffende Material nicht unter der genannten Creative Commons Lizenz steht und die betreffende Handlung nicht nach gesetzlichen Vorschriften erlaubt ist, ist für die oben aufgeführten Weiterverwendungen des Ma- terials die Einwilligung des jeweiligen Rechteinhabers einzuholen.

Weitere Details zur Lizenz entnehmen Sie bitte der Lizenzinformation auf http://creativecommons.org/ licenses/by/4.0/deed.de.

\section{Literatur}

1. Bekaert B, Kamalandua A, Zapico SC et al (2015) A selective set of DNA-methylation markers for age determination of blood, teeth and buccal samples. Forensic Sci Int Genet Suppl Ser 5:e144-e145

2. Daunay A, Baudrin LG, Deleuze JF et al (2019) Evaluation of six bloodbased age prediction models using DNA methylation analysis by pyrosequencing. Sci Rep 9:1-10

3. Dodge $Y$ (2008) The concise encyclopedia of statistics. Springer, Berlin Heidelberg

4. Freire-Aradas A, Phillips C, Lareu MV (2017) Forensic individual age estimation with DNA: from initial approaches to methylation tests. Forensic Sci Rev 29(2):121-144

5. Hannum G, Guinney J, Zhao Let al (2013) Genomewide methylation profiles reveal quantitative views of human aging rates. Mol Cell 49:359-367

6. Heyn H, Li N, Ferreira HJ et al (2012) Distinct DNA methylomes of newborns and centenarians. Proc Natl Acad Sci 109(26):10522-10527

7. Horvath S (2013) DNA methylation age of human tissues and cell types. Genome Biol 14. https://doi. org/10.1186/gb-2013-14-10-r115

8. Johansson $\AA$, Enroth S, Gyllensten U (2013) Continuous aging of the human DNA methylome throughout the human lifespan. Plos One 8 https://doi.org/10.1371/journal.pone.0067378

9. Jung SE, Lim SM, Hong SR et al (2019) DNA methylation of the ELOVL2, FHL2, KLF14, C1orf132/MIR29B2C, and TRIM59 genes for age prediction from blood, saliva, and buccal swab samples. Forensic Sci Int Genet 38:1-8

10. Johnson AA, Akman K, Calimport SRG et al (2012) The role of DNA Methylation in aging, rejuvenation, and age-related disease. Rejuvenation Res 15:483-494

11. Koch CM, Wagner W (2011) Epigenetic-agingsignature to determine age in different tissues. Aging 3:1018-1027

12. Naue J, Hoefsloot HCJ, Mook ORF et al (2017) Chronological age prediction based on DNA methylation: massive parallel sequencing and random forest regression. Forensic Sci Int Genet 31:19-28

13. Pfeifer M, Bajanowski T, Helmus J et al (2020) Interlaboratory adaption of age estimation models by DNA methylationanalysis-problems and solutions. Int J Legal Med 134(3):953-961

14. Thong Z, Chan XLS, Ying JYetal (2017) Evaluation of DNA methylation-based age prediction on blood. Forensic Sci Int Genet Suppl Ser 6:e249-e251

15. Tost J, Gut IG (2007) DNA methylation analysis by pyrosequencing. Nat Protoc 2:2265-2275

16. Vidaki A, Kayser M (2018) Recent progress, methods and perspectives in forensic epigenetics. Forensic Scilnt Genet 37:180-195

17. Weidner Cl, Lin Q, Koch CM et al (2014) Aging of blood can be tracked by DNA methylation changes at just three CpG sites. Genome Biol 15. https://doi. org/10.1186/gb-2014-15-2-r24

18. Zbiec-Piekarska R, Spólnicka M, Kupiec T et al (2015) Development of a forensically useful age prediction method based on DNA methylation analysis. Forensic Sci Int Genet 17:173-179
Aktuelle Informationen

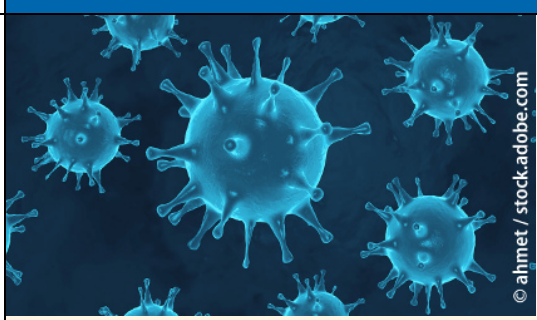

Aktuelle Beiträge zu COVID-19 in der Rechtsmedizin

Springer Nature und Springer Medizin unterstützen die globale Reaktion auf die COVID-19-Pandemie, indem ein schneller und direkter $\mathrm{Zu}$ gang zu den neuesten verfügbaren Forschungsergebnissen und Daten ermöglicht wird.

Auf der Homepage SpringerMedizin.de finden Sie ein immer aktuelles Dossier mit Beiträgen, Forschungsarbeiten und Ergebnissen zu SARS-CoV-2 sowie relevanten Links.

Darin z.B. auch die folgenden, frei

zugänglichen Beiträge aus der Rechtsmedizin zu COVID-19.

- COVID-19-assoziierte Sterbefälle, https://doi.org/10.1007/s00194-02100455-y

- SARS-CoV-2-assoziierte Todesfälle von erwachsenen Personen bis 50 Jahre, https://doi.org/10.1007/s00194-02100483-8

- SARS-CoV-2-Zufallsentdeckungen bei Hamburger Todesfällen: ein epidemiologisches Monitoring während des dynamischen Infektionsgeschehens im Frühjahr 2020, https://doi.org/10.1007/s00194021-00481-w

- Autoptische Darstellung des NasenRachen-Raumes bei Verdacht auf SARS-CoV2-Infektion, https://doi.org/10.1007/s00194-02100478-5

Das Dossier zu Coronavirus / Covid-19 von Springer Medizin finden Sie hier: www.springermedizin.de/covid-19

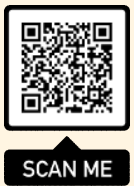

